\title{
Dysregulated inflammation may predispose patients with serious mental illnesses to severe COVID-19 (Review)
}

\author{
SERGEJ NADALIN ${ }^{1,2}$, HRVOJE JAKOVAC $^{3}$, VJEKOSLAV PEITL $^{4}$, \\ DALIBOR KARLOVIĆ ${ }^{4}$ and ALENA BURETIĆ-TOMLJANOVIĆ ${ }^{1}$
}

\author{
${ }^{1}$ Department of Medical Biology and Genetics, Faculty of Medicine, University of Rijeka, 51000 Rijeka; \\ ${ }^{2}$ Department of Psychiatry, General Hospital 'Dr. Josip Benčević', 35000 Slavonski Brod; ${ }^{3}$ Department of \\ Physiology and Immunology, Faculty of Medicine, University of Rijeka, 51000 Rijeka; ${ }^{4}$ Department of Psychiatry, \\ Sestre Milosrdnice University Hospital Center and Catholic University of Croatia, 10000 Zagreb, Croatia
}

Received March 21, 2021; Accepted May 21, 2021

DOI: $10.3892 / \mathrm{mmr} .2021 .12250$

\begin{abstract}
Genetic and nongenetic factors associated with an increased inflammatory response may mediate a link between severe coronavirus disease 2019 (COVID-19) and serious mental illness (SMI). However, systematic assessment of inflammatory response-related factors associated with SMI that could influence COVID-19 outcomes is lacking. In the present review, dietary patterns, smoking and the use of psychotropic medications are discussed as potential extrinsic risk factors and angiotensin-converting enzyme (ACE) insertion/deletion (I/D) gene polymorphisms are considered as potential intrinsic risk factors. A genetics-based prediction model for SMI using ACE-I/D genotyping is also proposed for use in patients experiencing severe COVID-19. Furthermore, the literature suggests that ACE inhibitors may have protective effects against SMI or severe COVID-19, which is often linked to hypertension and other cardiovascular comorbidities. For this reason, we hypothesize that using these medications to treat patients with severe COVID-19 might yield improved outcomes, including in the context of SMI associated with COVID-19.
\end{abstract}

\section{Contents}

1. Introduction

2. Psychotropic medications as possible modulators of COVID-19 severity with existing SMI

Correspondence to: Professor Sergej Nadalin, Department of Medical Biology and Genetics, Faculty of Medicine, University of Rijeka, Braće Branchetta 20, 51000 Rijeka, Croatia

E-mail: sergej.nadalin@medri.uniri.hr

Key words: angiotensin-converting enzyme, diet, inflammation, coronavirus disease 2019, psychotropic drugs, serious mental illness, smoking
3. Dietary factors as possible modulators of COVID-19 severity among patients with SMI

4. Cigarette smoking as a possible modulator of COVID-19 severity among patients with SMI

5. ACE polymorphisms

6. Conclusion

\section{Introduction}

Coronavirus disease 2019 (COVID-19), caused by severe acute respiratory syndrome-coronavirus 2 (SARS-CoV-2), was initially viewed as a primarily respiratory disease, leading to viral pneumonia in some cases. However, it is now recognized as a complex disease affecting various body systems (1). Among these effects, an accumulating body of research links severe COVID-19 to new-onset mental illness (2-5).

The data on whether mental illness affects the severity of COVID-19 are mixed. Studies indicate that the prevalence of COVID-19 among patients with serious mental illness (SMI) is either lower than (6) or similar to that among patients without a history of mental illness (7). However, patients with SMI are reported to have a slightly higher risk for severe clinical outcomes following infection with COVID-19 compared with those who do not have a history of mental illness (7). These findings suggest that COVID-19 and SMI might be reciprocal risk factors, raising the question of which pathways might link these two factors. A disadvantageous effect of SMIs on COVID-19 outcomes has been attributed primarily to medication non-adherence $(7,8)$ and cardiovascular comorbidities (7,9). Another potential explanation is that the shared attribute of increased inflammation may constitute the link between SMI and severe COVID-19 (10). Sedentary habits and low physical activity during COVID-19 quarantine have been associated with an inflammatory state and a negative impact on mental health (11-13).

Severe COVID-19 comprises the presence of pneumonia, severe acute respiratory distress syndrome, microvascular thrombosis and/or cytokine storms, all of which involve underlying inflammation (14). Numerous proinflammatory cytokines reportedly associated with severe COVID-19 (15) 
are also linked with SMIs, including schizophrenia, depression and bipolar affective disorder (16-19). Several recent reports have described new-onset depression in patients with COVID-19, accompanied by increased levels of interleukin-6, a key molecule in the cytokine storm $(4,10,20)$. These findings suggest that SMI-associated factors that could affect COVID-19 outcomes and vice versa should be investigated for their association with the inflammatory response. Thus far, the systematic evaluation of candidate factors is lacking (7).

In the present review, some of these candidate factors are critically discussed (Fig. 1). The initial focus is on psychotropic medication use, unhealthy dietary patterns and excessive smoking as potential extrinsic factors in existing mental illness that might heighten the risk of severe COVID-19. Next, the role of angiotensin-converting enzyme (ACE) insertion/deletion (I/D) gene polymorphisms as possible intrinsic factors in the development of both SMIs and COVID-19 is addressed. In addition, the possibility of using genetics-based methods to predict the new-onset SMI risk among patients experiencing severe COVID-19 is examined. Finally, some therapeutic options that might be relevant to the prevention of SMI onset following severe COVID-19 are proposed.

\section{Psychotropic medications as possible modulators of COVID-19 severity with existing SMI}

Previous studies have suggested that psychotropic medications could affect inflammatory processes. Various antipsychotics, antidepressants and antiepileptics have been shown to favor the anti-inflammatory state by increasing levels of anti-inflammatory cytokines and decreasing those of proinflammatory cytokines (21-24).

Antipsychotics. Clinical trials have shown that aspirin, estrogens, $\mathrm{N}$-acetylcysteine, minocycline, pregnenolone, celecoxib and $n-3$ polyunsaturated fatty acids (PUFAs) have antipsychotic effects (25). Other studies have indicated that by promoting an enhanced anti-inflammatory state, specific atypical antipsychotic medications may dysregulate innate and adaptive immune responses (Fig. 1), thereby increasing susceptibility to respiratory infections, including COVID-19 (26,27). In a preclinical study, the treatment of healthy mice with low-dose risperidone diminished the secretion of several important proinflammatory cytokines. In addition, risperidone inhibited an antibody response in the animals following vaccination with Pneumovax $23^{\circledR}(26)$. The latter observation is alarming, given increasing concerns about secondary bacterial pneumonia, including pneumococcal pneumonia, during COVID-19 (22). Furthermore, in a large group of individuals with schizophrenia-spectrum disorders $(n=6,309)$, among whom 102 tested positive for COVID-19, those treated with clozapine had a $~ 3$-fold increased risk for COVID-19 infection compared with those taking other antipsychotic medications (27). Several adverse effects of clozapine, including diabetes, obesity and hypersalivation (leading to aspiration pneumonia), have been proposed to contribute to the mechanism by which clozapine treatment affects COVID-19 risk (28). Moreover, clozapine treatment affects the innate immune system, leading to transient eosinophilia, cytokine release and fever during early treatment, and to neutropenia and agranulocytosis in a small minority of patients. Recent data also imply a link between clozapine treatment and adaptive immunity. Specifically, patients treated with clozapine experienced a significant reduction in all three classes of circulating immunoglobulins (M, A and G) compared with those treated with alternative antipsychotics (29).

The use of antipsychotics has also been reported to be associated with reduced physical activity, possibly because of the side effects of antipsychotics, which include extrapyramidal symptoms and fatigue $(30,31)$. However, physical activity supports immune function in viral respiratory infections by triggering the release of stress hormones, namely catecholamines and glucocorticoids, which are responsible for dampening local inflammation, and by promoting the secretion of anti-inflammatory cytokines $(11,12)$. Studies have demonstrated that physical activity also offers benefits for mental well-being and may prevent symptoms associated with depression and anxiety during COVID-19 quarantine $(11,32)$. One large study of people from the general population in Italy $(n=2,524)$ revealed that reduced total physical activity during quarantine had a negative effect on Psychological General Well-Being Index scores (11). Furthermore, a cross-national study involving people living in Germany, Italy, Russia and Spain indicated that individuals with symptoms of depression were at risk of a worsening psychological state during the COVID-19 pandemic and that physical activity counteracted this negative effect (32). The favorable effects of physical activity on psychological health have been attributed to stimulation of the cholinergic, dopaminergic and serotonergic neurotransmitter systems, endogenous opioid release and the expression of several trophic factors, including brain-derived neurotrophic factor $(13,33)$.

Antidepressants. Nonsteroidal anti-inflammatory medications, various pro-inflammatory cytokine inhibitors, statins, n-3 PUFAs, pioglitazone, minocyclin and modafinil have been indicated to exert antidepressant effects (34). Certain antidepressant medications from the selective serotonin reuptake inhibitor class, such as fluvoxamine, may exert favorable effects on patients with COVID-19 because of their immunomodulatory action. A preliminary clinical trial of fluvoxamine compared with placebo showed that adult patients with symptomatic COVID-19 treated with fluvoxamine had a lower likelihood of clinical deterioration and serious adverse events over 15 days (35). A protective effect of fluvoxamine in COVID-19 might arise from the ability of the drug to stimulate $\sigma-1$ receptor activity. The $\sigma-1$ receptor is an important endoplasmic reticulum chaperone protein with various cellular functions, including regulation of cytokine production (36). In addition, fluvoxamine accumulates in lysosomes, endosomes and biological membranes, where it interferes with the endosomal pathway and intracellular membrane trafficking crucial for viral infection (37).

Antiepileptics. Antiepileptics are regularly used to treat bipolar affective disorder, and are also prescribed to patients with schizophrenia at a lower rate, estimated at $20 \%(38,39)$. To the best of our knowledge, no studies have indicated a possible link between antiepileptic use and COVID-19 among patients with SMI. However, the use of antiepileptics has been reported to 


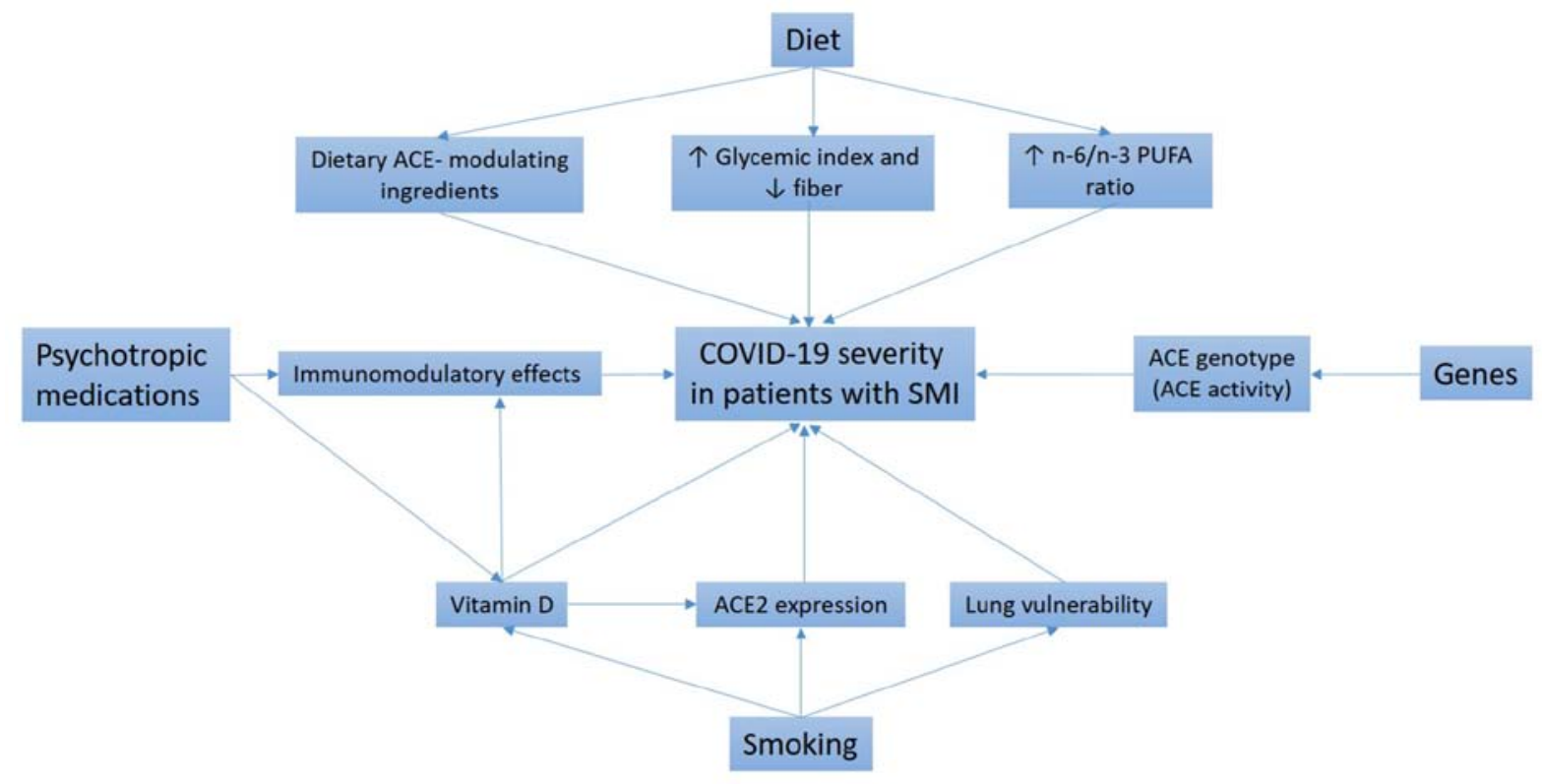

Figure 1. Proposed factors leading to more severe COVID-19 in patients with SMI. COVID-19, coronavirus disease 2019; SMI, serious mental illness; ACE, angiotensin-converting enzyme; PUFA, polyunsaturated fatty acids.

have an association with vitamin D deficiency (Fig. 1), which has been recognized as an important modulator of innate and adaptive immune responses (40). Several mechanisms have been proposed to explain the link between antiepileptic use and vitamin D deficiency (41-43). Certain antiepileptic drugs, for example, carbamazepine, phenobarbital, phenytoin, primidone and topiramate, induce the hepatic cytochrome system, leading to increased catabolism of the active form of vitamin D (1,25-dihydroxyvitamin D) (43). Furthermore, antiepileptic drugs may bind to the steroid and xenobiotic receptor transcription factor, potentially interacting with the vitamin D-responsive element for vitamin D-24-hydroxylase and thereby activating the enzyme $(41,43)$.

Vitamin D supplementation. Several studies have convincingly shown an association between vitamin $\mathrm{D}$ deficiency and COVID-19 severity (44,45). Recently conducted interventional clinical studies have further emphasized the importance of vitamin D in the prevention of severe COVID-19 outcomes $(46,47)$. Several mechanisms have been proposed for the protective effects of vitamin D in COVID-19 (Fig. 1), including immunomodulatory activity, the enhancement of defensin and interferon $\alpha$ expression, and initiation of local pro-regenerative processes $(48,49)$. The vitamin D-mediated reduction of proinflammatory cytokine hypersecretion is an important protective effect because of its role in preventing the development of a cytokine storm $(50,51)$. In addition, vitamin D deficiency is associated with accelerated thrombogenesis and a consequent increase in thrombotic episodes, which are frequently observed in patients with severe COVID-19 $(52,53)$.

\section{Dietary factors as possible modulators of COVID-19 severity among patients with SMI}

PUFAs. Dietary intake represents another important modulator of the inflammatory response (Fig. 1). Numerous studies have indicated that the dietary patterns of patients with SMI are characterized by a high intake of saturated fat and calories and a high n-6/n-3 PUFA ratio (54-59). These increases in saturated fat and the n-6/n-3 PUFA ratio are associated with an overall increase in the production of pro-inflammatory cytokines and an overreactive inflammatory response $(60,61)$. Furthermore, the consumption of monounsaturated fatty acids, fiber, fruit and vegetables, which exert potent anti-inflammatory effects, is often low among patients with SMI (54-59).

A number of PUFAs act as natural ligands of peroxisome proliferator-activated receptors (PPARs) and sterol regulatory element-binding protein (SREBP) transcription factors, which regulate lipid and glucose metabolism, and overall energy homeostasis (62-64). Thus, an unbalanced n-6/n-3 PUFA ratio in patients with SMI could indirectly contribute to diabetes, dyslipidemia and obesity risk via PPAR and SREBP transcriptional activation. This speculation may be relevant to COVID-19 because a greater risk of severe outcomes has been reported among individuals with diabetes, dyslipidemia and/or obesity $(65,66)$.

A dietary deficiency of n-3 PUFAs can lead to changes in the phospholipid fatty acid composition of membranes, and thereby induce changes in the collective physicochemical properties of the bilayer, such as flexibility and fluidity (67). These modifications can affect the function of membrane proteins that mediate the action of insulin, such as glucose transporter type 4, and lead to insulin resistance, diabetes and dyslipidemia (67-69). In addition, in vitro studies have indicated that membrane n-3 PUFA levels influence the therapeutic efficiency of psychotropic drugs, as n-3 PUFAs facilitate the intercalation of the drugs between acidic glycerophospholipids (68).

Fermented foods. Notably, an article by Bousquet et al (70) published during the first pandemic wave in the spring of 2020 indicated that diet may play a role in the immune defense 
against COVID-19 and could explain some differences in COVID-19 mortality risk. Specifically, the authors proposed an association between the consumption of foods with potent anti-ACE activity and a low prevalence of COVID-19 mortalities. These foods include uncooked or fermented cabbage, which is widely consumed in a number of European countries with low mortality rates, as well as in Korea and Taiwan. Furthermore, fermented milk, another natural ACE inhibitor, is widely consumed in Bulgaria, Greece and Turkey, all of which also have had relatively low mortality rates. These findings may be mechanistically explained by a reduced production of angiotensin II (Ang II), which can act as a proinflammatory molecule, contributing to acute lung injury and favoring more severe COVID-19 manifestations $(71,72)$. In addition, the microbiota present in fermented dairy products is linked to the induction of gut-mediated pulmonary immunity, providing protection against respiratory infections and inflammation (73-75).

Fruit, vegetable, and fiber intake. Recently, Abdulah and Hassan (76) explored COVID-19 infection and mortality rates in the context of dietary factors among 158 countries worldwide and identified a clear association of dietary patterns with epidemiological variables. Their data demonstrated strong positive correlations between a higher intake of fruits and SARS-CoV-2 infection, and between sugar-sweetened beverages and COVID-19 mortality. By contrast, they found that a higher intake of beans and legumes was associated with a negative effect on infection and mortality rates, suggesting that foods with a high glycemic index may be a risk factor for infection or mortality. Such findings could be explained by an excess caloric intake leading to weight gain, obesity and insulin resistance, which have been strongly linked to a hyperinflammatory response during viral infections, as well as to a generally higher respiratory infection rate $(77,78)$. By contrast, beans and legumes are known for their low glycemic index, and contain the essential amino acids and micronutrients required for an appropriate and precisely targeted immune response $(79,80)$. Furthemore, dietary fiber, abundantly present in a legume-rich diet, creates a suitable milieu for the survival and growth of gut microbiota and provides metabolic precursors for secondary bacterial metabolites that affect immunity and neurotransmission $(81,82)$.

\section{Cigarette smoking as a possible modulator of COVID-19 severity among patients with SMI}

The estimated prevalence of smoking among people with SMI is $50-80 \%$ worldwide, which is significantly higher than that in the general population, and people with SMI are also more likely to smoke heavily, considered as $\geq 30$ cigarettes or 1.5 packs daily (83-85). The reported prevalence of smoking among patients with schizophrenia is higher than that in patients with bipolar disorder or depression $(86,87)$. Several mechanisms have been proposed to explain the link between cigarette smoke and inflammation, such as an imbalanced ratio of pro-inflammatory and anti-inflammatory cytokines, impairment of the innate immune response and increased oxidative stress $(88,89)$.
Smoking and COVID-19. Studies of patients with COVID-19 have identified cigarette smoking as an important risk factor for severe outcomes (90-92) (Fig. 1). The elevated rates of severe COVID-19 in individuals who smoke may be attributable to diseases associated with smoking, for example, chronic obstructive pulmonary disease, diabetes and cardiovascular disease $(90,92)$. Furthermore, cigarette smoke has been proposed to increase expression of the ACE2 receptor in the bronchial epithelium (Fig. 1). This receptor is the mediator of SARS-CoV-2 entry into host cells $(90,91)$. However, considering the anti-inflammatory properties of ACE2, certain studies have claimed that the upregulation of ACE2 by smoking may exert a protective effect against COVID-19 rather than a harmful one $(93,94)$. One possible explanation for this is that the ACE2-mediated cleavage of detrimental Ang II becomes more efficient and subsequently increases the production of angiotensins 1-7 (Ang 1-7), which show anti-inflammatory and proregenerative activity $(71,95)$. Moreover, the nitric oxide produced during smoking promotes the maintenance of airway dilation and filtration prior to its entry into the lungs $(94,96)$ and also inhibits the replication of SARS-CoV-2 in vitro $(94,97)$.

Smoking, SMI medications and COVID-19. Among people with SMI, smoking is likely to interact with factors modulating vulnerability to COVID-19, such as the use of psychotropic medications and maintenance of an unhealthy dietary pattern (98-101). For instance, smoking has been shown to increase the clearance of specific antipsychotics, namely clozapine and olanzapine, and antidepressants, namely fluvoxamine, duloxetine, mirtazapine and trazodone, by inducing their metabolism in the liver, suggesting that smokers may be at risk of undertreatment $(98,101)$. In addition, nicotine has been reported to have inhibitory effects on the activity and concentration of various antiepileptic medications, including lamotrigine, carbamazepine, diphenylhydantoin, phenobarbital and topiramate in animals (98), while cigarette smoking was shown to reduce serum levels of lamotrigine in a clinical study (99).

Smoking, diet and COVID-19. Certain studies have indicated a link between smoking and an unhealthy or proinflammatory dietary pattern among patients with SMI $(57,102,103)$. For instance, smokers with schizophrenia are reported to be more likely to consume salt and saturated fat, and less likely to follow a high-fiber and low-calorie diet compared with nonsmokers (102). In addition, among individuals with depression, current smokers reported consuming more high-fat foods compared with never smokers and more fast-food fats compared with former and never smokers (103). Furthermore, several reports suggest a poorer diet accompanied by lower levels of physical activity among smokers with bipolar disorder compared with healthy individuals (104-106).

Smoking, vitamin D deficiency and COVID-19. Smoking has been identified as an important factor contributing to vitamin D deficiency (Fig. 1) among patients with SMI $(107,108)$. A suggested mechanism for the link between smoking and vitamin D deficiency is that cigarette smoke decreases the production of 1,25-dihydroxyvitamin $\mathrm{D}$ in lung 
epithelial cells $(109,110)$. In addition, various cigarette smoke extracts have been demonstrated to inhibit translocation of the vitamin $\mathrm{D}$ receptor from the nucleus to microsome in human alveolar basal epithelial cell line (111).

\section{ACE polymorphisms}

ACE polymorphism overview. Genetic variations have been proposed to play a role in vulnerability to SMIs (112-114) as well as to COVID-19 (115-117). To the best of our knowledge, no studies have established a direct genetic link between COVID-19 and SMI. However, several findings suggest the possibility that the ACE gene might be relevant to both SMI and COVID-19 (Fig. 1). Within the renin-angiotensin system (RAS), ACE produces pro-inflammatory Ang II, which is in turn cleaved by ACE2, resulting in the formation of anti-inflammatory Ang1-7. Given this association, ACE activity can be considered proinflammatory, whereas ACE2 exerts anti-inflammatory effects by opposing ACE (71,72). A functional insertion/deletion (I/D) polymorphism (rs1799752) in intron 16 of the ACE gene is the most studied RAS-associated polymorphic variant and (118) has been investigated among patients with SMI (119-128). This ACE-I/D polymorphism accounts for $\sim 50 \%$ of the variance in serum ACE levels; individuals homozygous for the $\mathrm{D}$ allele have the highest $\mathrm{ACE}$ levels, individuals homozygous for the I allele have the lowest ACE levels, and those who are heterozygous for the I and D alleles exhibit intermediate levels (118).

ACE polymorphisms in SMI. Results of a meta-analysis that included a large number of participants $(n=10,223)$ in case-control studies indicated that the ACE-DD homozygous genotype was associated with an elevated risk of depression in a Caucasian and mixed ethnic group consisting of several European populations (German, British, Belgian, Finish and Israeli) and Asian populations (Japanese and Chinese) (119). Several studies have indicated that the ACE-I/D polymorphism might be associated with an elevated risk of schizophrenia, although the results were conflicting (120-122) and not confirmed in a meta-analysis (123). A greater risk for schizophrenia was observed among individuals carrying the ACE-D allele (ACE-DD homozygous and ACE-ID heterozygous) in the Turkish and Iranian populations $(120,121)$, and among those carrying the ACE-I allele (ACE-II homozygous and ACE-ID heterozygous) in the Spanish population (122). Furthermore, a greater severity of schizophrenia, based on Positive and Negative Syndrome Scale psychopathology evaluations (124-126) and improved response to specific antidepressants, was detected among individuals who were ACE-DD homozygous and ACE-D carriers $(127,128)$.

ACE polymorphisms in COVID-19. A number of studies have assessed the relevance of the ACE-I/D polymorphism in COVID-19-associated deaths. During the first wave of the pandemic, Delanghe et al (129) compared the D-allele frequency of the ACE gene in 25 European countries with the prevalence and mortality rates of COVID-19. The authors concluded that the prevalence of COVID-19 and mortality were negatively correlated with frequency of the ACE-D allele, indicating that this allele might be protective. The protective effects of this allele against COVID-19 prevalence and mortality were supported by a further study from the same research team, in which COVID-19 risk and ACE-I/D polymorphism were assessed in 33 countries from Europe, North Africa and the Middle East (130). In that study, the authors also assessed whether COVID-19 infection was correlated with additional immune system-associated human plasma protein polymorphisms, including the $\mathrm{F}$ and $\mathrm{S}$ alleles of complement $\mathrm{C} 3$, the $\mathrm{C} 282 \mathrm{Y}$ mutation of homeostatic iron regulator (HFE), the $\mathrm{Hp} 1$ and $\mathrm{Hp} 2$ alleles of haptoglobin, and the DBP1 and DBP2 alleles of vitamin D-binding protein; however, no significant associations were detected. The ACE-D allele results in higher ACE activity, favoring a more intense inflammatory response through increased production of Ang II. According to the principle of classical competitive inhibition, such findings may be explained in part by the competition between large amounts of Ang II, which is the ACE2 substrate, and SARS-CoV-2 in binding to the ACE2 receptor. However, a meta-analysis of ACE-D allele distribution in various European countries revealed high frequencies in Spain, Italy and the United Kingdom (131), which are among those most severely affected by COVID-19. Thus, the ACE-D allele may be a harmful rather than a protective factor in COVID-19.

Given the association of ACE-DD with the highest ACE activity and consequently high production levels of proinflammatory and profibrotic Ang II, Bellone and Calvisi (132) examined the correlation of COVID-19-associated deaths with ACE-DD and ACE-II genotypes in 25 European countries. The authors detected a significant positive correlation between ACE-DD frequency and COVID-19-associated deaths. By contrast, the ACE-II genotype frequency was inversely correlated with COVID-19-associated deaths, and no correlation was found between ACE-ID and COVID-19-associated mortality. The relevance of ACE-I/D polymorphism to COVID-19 severity was evaluated in a global meta-analysis including a high number of participants $(n=48,758)$ from 30 countries. The authors investigated COVID-19 recovery and mortality rates according to the ACE-I/D allele frequency ratio (133). They found that an increased ACE-I/D allele ratio was associated with an increased rate of recovery, but identified no significant association between mortality rate and the ACE-I/D ratio.

Role of ACE inhibitors. The disadvantageous effects in COVID-19 of the ACE-DD homozygous genotype and, by implication, high ACE activity (118), is supported by recent clinical studies showing a lower rate of severe disease and lower all-cause mortality among patients with COVID-19 whose hypertension was being treated with ACE inhibitors (134-137). In addition, evidence suggests that an abrupt suspension of ACE inhibitors in patients with COVID-19 and cardiovascular disease may result in clinical deterioration and worse outcomes $(136,138,139)$. In addition, the results of some preclinical studies suggested that ACE inhibition shows promise in the mitigation of psychotic symptomatology and cognitive deficits (140-142). Furthermore, human studies have indicated that ACE inhibitors may have favorable effects on cognitive deficits in schizophrenia, possibly by modulating the cleavage of specific neuropeptides, such as substance $\mathrm{P}$ and neurotensin $(141,142)$. 
ACE polymorphisms and risk for SMI after COVID-19. As aforementioned, ACE-I/D polymorphisms have potential relevance in SMI $(119,120-123)$ and severe COVID-19 $(129,130,132,133)$. In addition, severe COVID-19 has been associated with increased post-infection occurrence of SMI (2-5), probably in predisposed individuals (115-117). For these reasons, the genotyping of individuals with severe COVID-19 might be useful for predicting COVID-19 outcomes and new-onset SMI associated with COVID-19. Moreover, using ACE inhibitors to treat patients with severe COVID-19 might yield more favorable outcomes, not only for mitigating the disease but also for preventing the development of SMI as a secondary effect of COVID-19.

\section{Conclusion}

SMI and severe COVID-19 appear to have an increased inflammatory response in common. Numerous extrinsic and intrinsic factors may act as modulators of inflammatory processes among patients with SMI. Extrinsic factors, such as an unhealthy dietary pattern and excessive smoking, could contribute to the etiology of severe COVID-19 in people with SMI, as in the general population, but are potentially modifiable through lifestyle changes. In addition, physical activity, which has been reduced during COVID-19 quarantine, is relevant to the ability of the immune system to defend against viral infection, as well as to psychological health and well-being. However, the etiopathogenesis of severe COVID-19 may be heterogeneous among patients with SMI because of interactions among these factors, antipsychotic medications and genetic polymorphisms, such as ACE-I/D. Within the RAS, ACE simultaneously promotes the inflammatory reponse and counteracts the activity of ACE2, the host receptor that mediates SARS-CoV-2 cell entry. Several studies support the relevance of the functional ACE-I/D polymorphism in both SMI and severe COVID-19. For this reason, genotyping individuals with severe COVID-19 for the ACE-I/D polymorphism might offer predictive utility for COVID-19 outcomes and the risk of new-onset, COVID-19-associated SMI. Furthermore, ACE inhibitors exhibit promise for the mitigation of psychotic symptomatology and cognitive deficits, and their positive effects in severe COVID-19 accompanied by hypertension and other cardiovascular comorbidities have been reported. Thus, the administration of ACE inhibitors to patients with severe COVID-19 might be of benefit in the mitigation of severe disease and prevention of new-onset SMI secondary to COVID-19 disease.

\section{Acknowledgements}

Not applicable.

\section{Funding}

This study was supported by grants fromthe University of Rijeka, Croatia (grant nos. 17.07.2.1.10 and uniri-biomed-18-251). The university had no further role in the study design; data collection, analysis or interpretation; or the decision to submit this paper for publication.

\section{Availability of data and materials}

Not applicable.

\section{Authors' contributions}

SN and HJ designed the study and wrote the manuscript. VP, DK and ABT wrote and drafted the manuscript. Data authentication is not applicable. All authors read and approved the final manuscript.

\section{Ethics approval and consent to participate}

Not applicable.

\section{Patient consent for publication}

Not applicable.

\section{Competing interests}

The authors declare that they have no competing interests.

\section{References}

1. Roberts CM, Levi M, McKee M, Schilling R, Lim WS and Grocott MPW: COVID-19: A complex multisystem disorder. $\mathrm{Br}$ J Anaesth 125: 238-242, 2020.

2. Chacko M, Job A, Caston F III, George P, Yacoub A and Cáceda R: COVID-19-induced psychosis and suicidal behavior: Case report. SN Compr Clin Med 26: 1-5, 2020.

3. Ferrando SJ, Klepacz L, Lynch S, Tavakkoli M, Dornbush R, Baharani R, Smolin Y and Bartell A: COVID-19 psychosis: A potential new neuropsychiatric condition triggered by novel coronavirus infection and the inflammatory response? Psychosomatics 6: 551-555, 2020.

4. Mazza MG, De Lorenzo R, Conte C, Poletti S, Vai B, Bollettini I, Melloni EMT, Furlan R, Ciceri F, Rovere-Querini P, et al: Anxiety and depression in COVID-19 survivors: Role of inflammatory and clinical predictors. Brain Behav Immun 89: 594-600, 2020.

5. Anjum S, Ullah R, Rana MS, Khan HA, Memon FS, Ahmed Y, Jabeen S and Faryal R: COVID-19 pandemic: A serious threat for public mental health globally. Psychiatr Danub 32: 245-250, 2020.

6. El-Khoury F, Cuenca M, Niel P and Masson VD: Low prevalence of SARS-CoV-2 among patients presenting at a Parisian psychiatry University Hospital Group. Eur J Psychiatry: Sep 24, 2020 (Epub ahead of print).

7. Lee SW, Yang JM, Moon SY, Yoo IK, Ha EK, Kim SY, Park UM, Choi S, Lee SH, Ahn YM, et al: Association between mental illness and COVID-19 susceptibility and clinical outcomes in South Korea: A nationwide cohort study. Lancet Psychiatry 7: 1025-1031, 2020.

8. DiMatteo MR, Lepper HS and Croghan TW: Depression is a risk factor for noncompliance with medical treatment: Meta-analysis of the effects of anxiety and depression on patient adherence. Arch Intern Med 160: 2101-2107, 2000.

9. Nicholson A, Kuper H and Hemingway H: Depression as an aetiologic and prognostic factor in coronary heart disease: A meta-analysis of 6362 events among 146538 participants in 54 observational studies. Eur Heart J 27: 2763-2774, 2006.

10. Alpert O, Begun L, Garren P and Solhkhah R: Cytokine storm induced new onset depression in patients with COVID-19. A new look into the association between depression and cytokines-two case reports. Brain Behav Immun Health 9: 100173, 2020.

11. Maugeri G, Castrogiovanni P, Battaglia G, Pippi R, D'Agata V, Palma A, Di Rosa M and Musumeci G: The impact of physical activity on psychological health during Covid-19 pandemic in Italy. Heliyon 6: e04315, 2020.

12. Ravalli S and Musumeci G: Coronavirus outbreak in Italy: Physiological benefits of home-based exercise during pandemic. J Funct Morphol Kinesiol 5: 31, 2020. 
13. Maugeri G and Musumeci G: Adapted physical activity to ensure the physical and psychological well-being of COVID-19 patients. J Funct Morphol Kinesiol 6: 13, 2021.

14. Weir EK, Thenappan T, Bhargava M and Chen Y: Does vitamin D deficiency increase the severity of COVID-19? Clin Med (Lond) 20: e107-e108, 2020.

15. Leisman DE, Ronner L, Pinotti R, Taylor MD, Sinha P, Calfee CS, Hirayama AV, Mastroiani F, Turtle CJ, Harhay MO, et al: Cytokine elevation in severe and critical COVID-19: A rapid systematic review, meta-analysis, and comparison with other inflammatory syndromes. Lancet Respir Med 8: 1233-1244, 2020.

16. Goldstein BI, Kemp DE, Soczynska JK and McIntyre RS: Inflammation and the phenomenology, pathophysiology, comorbidity, and treatment of bipolar disorder: A systematic review of the literature. J Clin Psychiatry 70: 1078-1090, 2009.

17. Farooq RK, Asghar K, Kanwal S and Zulqernain A: Role of inflammatory cytokines in depression: Focus on interleukin-1 $\beta$ Biomed Rep 6: 15-20, 2017.

18. Himmerich H, Patsalos O, Lichtblau N, Ibrahim MAA and Dalton B: Cytokine research in depression: Principles, challenges, and open questions. Front Psychiatry 10: 30, 2019.

19. Momtazmanesh S, Zare-Shahabadi A and Rezaei N: Cytokine alterations in schizophrenia: An updated review. Front Psychiatry 10: 892, 2019.

20. Zhang J, Lu H, Zeng H, Zhang S, Du Q, Jiang T and Du B: The differential psychological distress of populations affected by the COVID-19 pandemic. Brain Behav Immun 87: 49-50, 2020.

21. Stienen MN, Haghikia A, Dambach H, Thöne J, Wiemann M, Gold R, Chan A, Dermietzel R, Faustmann PM, Hinkerohe D and Prochnow N: Anti-inflammatory effects of the anticonvulsant drug levetiracetam on electrophysiological properties of astroglia are mediated via TGF $\beta 1$ regulation. Br J Pharmacol 162: 491-507, 2011.

22. Hoşgörler F, Keleş D, Tanrıverdi-Akhisaroğlu S, İnanç Ş, Akhisaroğlu M, Cankurt Ü, Aydoğdu Z, Uçar AD, Çetinayak O, Oktay G and Arda SG: Anti-inflammatory and Anti-apoptotic effect of valproic acid and doxycycline independent from MMP inhibition in early radiation damage. Balkan Med J 33: 488-495, 2013.

23. Al-Amin MM, Nasir Uddin MM and Mahmud Reza H: Effects of antipsychotics on the inflammatory response system of patients with schizophrenia in peripheral blood mononuclear cell cultures Clin Psychopharmacol Neurosci 11: 144-151, 2013.

24. FourrierC,Sampson E,Mills NT and Baune BT: Anti-inflammatory treatment of depression: Study protocol for a randomised controlled trial of vortioxetine augmented with celecoxib or placebo. Trials 19: 447, 2018.

25. Cho M, Lee TY, Kwak YB, Yoon YB, Kim M and Kwon JS: Adjunctive use of anti-inflammatory drugs for schizophrenia: A meta-analytic investigation of randomized controlled trials. Aust N Z J Psychiatry 53: 742-759, 2019.

26. May M, Slitzky M, Rostama B, Barlow D and Houseknecht KL: Antipsychotic-induced immune dysfunction: A consideration for COVID-19 risk. Brain Behav Immun Health 6: 100097, 2020.

27. Govind R, Fonseca de Freitas D, Pritchard M, Hayes RD and MacCabe JH: Clozapine treatment and risk of COVID-19 infection: Retrospective cohort study. Br J Psychiatry 27: 1-7, 2020.

28. Gurrera RJ and Perry NL: Clozapine-associated aspiration pneumonia: Case series and review of the literature: Reply. Psychosomatics 60: 103, 2019.

29. Ponsford M, Castle D, Tahir T, Robinson R, Wade W, Steven R, Bramhall K, Moody M, Carne E, Ford C, et al: Clozapine is associated with secondary antibody deficiency. Br J Psychiatry 214: $1-7,2018$.

30. Vancampfort D, Probst M, Daenen A, Damme TV, De Hert M, Rosenbaum S and Bruyninckx D: Impact of antipsychotic medication on physical activity and physical fitness in adolescents: An exploratory study. Psychiatry Res 242: 192-197, 2016.

31. Perez-Cruzado D, Cuesta-Vargas A, Vera-Garcia E and Mayoral-Cleries F: Medication and physical activity and physical fitness in severe mental illness. Psychiatry Res 267: 19-24, 2018.

32. Brailovskaia J, Cosci F, Mansueto G, Miragall M, Herrero R, Baños RM, Krasavtseva Y, Kochetkov Y and Margraf J: The association between depression symptoms, psychological burden caused by Covid-19 and physical activity: An investigation in Germany, Italy, Russia, and Spain. Psychiatry Res 295: 113596, 2021.

33. Phillips C: Brain-Derived neurotrophic factor, depression, and physical activity: Making the neuroplastic connection. Neural Plast 2017: 7260130, 2017
34. Köhler-Forsberg O, N Lydholm C, Hjorthøj C, Nordentoft M, Mors $\mathrm{O}$ and Benros ME: Efficacy of anti-inflammatory treatment on major depressive disorder or depressive symptoms: Meta-analysis of clinical trials. Acta Psychiatr Scand 139: 404-419, 2019.

35. Lenze EJ, Mattar C, Zorumski CF, Stevens A, Schweiger J, Nicol GE, Miller JP, Yang L, Yingling M, Avidan MS and Reiersen AM: Fluvoxamine vs placebo and clinical deterioration in outpatients with symptomatic COVID-19: A randomized clinical trial. JAMA 324: 2292-2300, 2020.

36. Ishima T, Fujita $\mathrm{Y}$ and Hashimoto $\mathrm{K}$ : Interaction of new antidepressants with sigma-1 receptor chaperones and their potentiation of neurite outgrowth in PC12 cells. Eur J Pharmac 727: 167-173, 2014.

37. Homolak $\mathbf{J}$ and Kodvanj I: Widely available lysosome targeting agents should be considered as potential therapy for COVID-19. Int J Antimicrob Agents 56: 106044, 2020.

38. Nadkarni S and Devinsky O: Psychotropic effects of antiepileptic drugs. Epilepsy Curr 5: 176-181, 2005.

39. Grunze HC: The effectiveness of anticonvulsants in psychiatric disorders. Dialogues Clin Neurosci 10: 77-89, 2008.

40. Aranow C: Vitamin D and the immune system. J Investig Med 59: 881-886, 2011

41. Menon B and Harinarayan CV: The effect of anti epileptic drug therapy on serum 25-hydroxyvitamin D and parameters of calcium and bone metabolism-a longitudinal study. Seizure 19: 153-158, 2010.

42. Teagarden DL, Meador KJ and Loring DW: Low vitamin D levels are common in patients with epilepsy. Epilepsy Res 108: 1352-1356, 2014.

43. Chaudhuri JR, Mridula KR, Rathnakishore C, Balaraju B and Bandaru VS: Association of 25-Hydroxyvitamin D Deficiency in pediatric epileptic patients. Iran J Child Neurol 11: 48-56, 2017.

44. Mariani J, Giménez VMM, Bergam I, Tajer C, Antonietti L, Inserra F, Ferder L and Manucha W: Association between vitamin D deficiency and COVID-19 incidence, complications, and mortality in 46 countries: An ecological study. Health Secur 19: 302-308, 2021.

45. Jain A, Chaurasia R, Sengar NS, Singh M, Mahor S and Narain S: Analysis of vitamin D level among asymptomatic and critically ill COVID-19 patients and its correlation with inflammatory markers. Sci Rep 10: 20191, 2020.

46. Entrenas Castillo M, Entrenas Costa LM, Vaquero Barrios JM Alcalá Díaz JF, López Miranda J, Bouillon $R$ and Quesada Gomez JM: 'Effect of calcifediol treatment and best available therapy versus best available therapy on intensive care unit admission and mortality among patients hospitalized for COVID-19: A pilot randomized clinical study'. J Steroid Biochem Mol Biol 203: 105751, 2020.

47. Tan CW, Ho LP, Kalimuddin S, Cherng BPZ, Teh YE, Thien SY, Wong HM, Tern PJW, Chandran M, Chay JWM, et al: Cohort study to evaluate the effect of vitamin $\mathrm{D}$, magnesium, and vitamin $\mathrm{B}_{12}$ in combination on progression to severe outcomes in older patients with coronavirus (COVID-19). Nutrition 79-80: 111017, 2020

48. Jakovac H: COVID-19 and vitamin D-Is there a link and an opportunity for intervention? Am J Physiol Endocrinol Metab 318: E589, 2020.

49. Ahmed F: A network-based analysis reveals the mechanism underlying vitamin $\mathrm{D}$ in suppressing cytokine storm and virus in SARS-CoV-2 infection. Front Immunol 11: 590459, 2020

50. Aygun H: Vitamin D can prevent COVID-19 infection-induced multiple organ damage. Naunyn Schmiedebergs Arch Pharmacol 393: 1157-1160, 2020.

51. Kumar R, Rathi H, Haq A, Wimalawansa SJ and Sharma A Putative roles of vitamin $\mathrm{D}$ in modulating immune response and immunopathology associated with COVID-19. Virus Res 292: 198235, 2021

52. Verdoia M, Pergolini P, Nardin M, Rolla R, Negro F, Kedhi E, Suryapranata H, Marcolongo M, Carriero A and De Luca G; Novara Atherosclerosis Study Group (NAS): Vitamin D levels and platelet reactivity in diabetic patients receiving dual antiplatelet therapy. Vascul Pharmacol 120: 106564, 2019.

53. Zabetakis I, Lordan R, Norton C and Tsoupras A: COVID-19: The inflammation link and the role of nutrition in potential mitigation. Nutrients 12: 1466, 2020.

54. McCreadie RG; Scottish Schizophrenia Lifestyle Group: Diet, smoking and cardiovascular risk in people with schizophrenia: Descriptive study. Br J Psychiatry 183: 534-539, 2003.

55. Henderson DC, Borba CP, Daley TB, Boxill R, Nguyen DD, Culhane MA,Louie P,CatherC,Eden Evins A,Freudenreich O, et al: Dietary intake profile of patients with schizophrenia. Ann Clin Psychiatry 18: 99-105, 2006. 
56. Amani R: Is dietary pattern of schizophrenia patients different from healthy subjects? BMC Psychiatry 7: 15, 2007.

57. Dipasquale S, Pariante CM, Dazzan P, Aguglia E, McGuire P and Mondelli V: The dietary pattern of patients with schizophrenia: A systematic review. J Psychiatr Res 47: 197-207, 2013.

58. Firth J, Stubbs B, Teasdale SB, Ward PB, Veronese N, Shivappa N, Hebert JR, Berk M, Yung AR and Sarris J: Diet as a hot topic in psychiatry: A population-scale study of nutritional intake and inflammatory potential in severe mental illness. World Psychiatry 17: 365-367, 2018.

59. Teasdale SB, Ward PB, Samaras K, Firth J, Stubbs B, Tripodi E and Burrows TL: Dietary intake of people with severe mental illness: Systematic review and meta-analysis. Br J Psychiatry 214: 251-259, 2019.

60. Milanski M, Degasperi G, Coope A, Morari J, Denis R, Cintra DE, Tsukumo DM, Anhe G, Amaral ME, Takahashi HK, et al: Saturated fatty acids produce an inflammatory response predominantly through the activation of TLR4 signaling in hypothalamus: Implications for the pathogenesis of obesity. J Neurosci 29: 359-370, 2009.

61. Patterson E, Wall R, Fitzgerald GF, Ross RP and Stanton C: Health implications of high dietary omega- 6 polyunsaturated Fatty acids. J Nutr Metab 2012: 539426, 2012.

62. Jump DB, Botolin D, Wang Y, Xu J and Christian B: Fatty acids and gene transcription. Food Nutr Res 50 (Suppl 2): 5-12, 2006.

63. Stienstra R, Duval C, Müller M and Kersten S: PPARs, obesity, and inflammation. PPAR Res 2007: 95974, 2007.

64. Muralikumar S, Vetrivel U, Narayanasamy A and N Das U: Probing the intermolecular interactions of PPAR $\gamma$-LBD with polyunsaturated fatty acids and their anti-inflammatory metabolites to infer most potential binding moieties. Lipids Health Dis 16: 17, 2017.

65. Choi GJ, Kim HM and Kang H: The potential role of dyslipidemia in COVID-19 severity: An umbrella review of systematic reviews. J Lipid Atheroscler 9: 435-448, 2020.

66. Zhou F, Yu T, Du R, Fan G, Liu Y, Liu Z, Xiang J, Wang Y, Song B, $\mathrm{Gu} \mathrm{X}$, et al: Clinical course and risk factors for mortality of adult inpatients with COVID-19 in Wuhan, China: A retrospective cohort study. Lancet 395: 1054-1062, 2020.

67. Perona JS: Membrane lipid alterations in the metabolic syndrome and the role of dietary oils. Biochim Biophys Acta Biomembr 1859 (9 Pt B): 1690-1703, 2017.

68. Oruch R, Lund A, Pryme IF and Holmsen H: An intercalation mechanism as a mode of action exerted by psychotropic drugs: Results of altered phospholipid substrate availabilities in membranes? J Chem Biol 3: 67-88, 2010.

69. Leguisamo NM, Lehnen AM, Machado UF, Okamoto MM Markoski MM, Pinto GH and Schaan BD: GLUT4 content decreases along with insulin resistance and high levels of inflammatory markers in rats with metabolic syndrome. Cardiovasc Diabetol 11: 100, 2012

70. Bousquet J, Anto JM, Iaccarino G, Czarlewski W, Haahtela T, Anto A, Akdis CA, Blain H, Canonica GW, Cardona V, et al: Is diet partly responsible for differences in COVID-19 death rates between and within countries? Clin Transl Allergy 10: 16, 2020.

71. Jakovac H: COVID-19: Is the ACE2 just a foe? Am J Physiol Lung Cell Mol Physiol 318: L1025-L1026, 2020.

72. Warner FJ, Rajapaksha H, Shackel N and Herath CB: ACE2: From protection of liver disease to propagation of COVID-19. Clin Sci (Lond) 134: 3137-3158, 2020.

73. Gohil K, Samson R, Dastager S and Dharne M: Probiotics in the prophylaxis of COVID-19: Something is better than nothing. 3 Biotech 11: 1,2021.

74. Karl JP: Gut Microbiota-targeted interventions for reducing the incidence, duration, and severity of respiratory tract infections in healthy non-elderly adults. Mil Med 186: e310-e318, 2021

75. Hamida RS, Shami A, Ali MA, Almohawes ZN, Mohammed AE and Bin-Meferij MM: Kefir: A protective dietary supplementation against viral infection. Biomed Pharmacother 133: 110974, 2021.

76. Abdulah DM and Hassan AB: Relation of dietary factors with infection and mortality rates of COVID-19 across the World. J Nutr Health Aging 24: 1011-1018, 2020.

77. Falagas ME and Kompoti M: Obesity and infection. Lancet Infect Dis 6: 438-446, 2006

78. Karlsson EA and Beck MA: The burden of obesity on infectious disease. Exp Biol Med (Maywood) 235: 1412-1424, 2010.

79. Li P, Yin YL, Li D, Kim SW and Wu G: Amino acids and immune function. Br J Nutr 98: 237-252, 2007.

80. Jenkins DJA, Srichaikul KK, Kendall CWC and Sievenpiper JL: Bean, fruit, and vegetable fiber, but not cereal fiber are associated with reduced mortality in Japan. Am J Clin Nutr 111: 941-943, 2020 .
81. Gill SK, Rossi M, Bajka B and Whelan K: Dietary fibre in gastrointestinal health and disease. Nat Rev Gastroenterol Hepatol 18 101-116, 2021.

82. Yao T, Chen MH and Lindemann SR: Structurally complex carbohydrates maintain diversity in gut-derived microbial consortia under high dilution pressure. FEMS Microbiol Ecol 96 fiaa158, 2020.

83. Vanable PA, Carey MP, Carey KB and Maisto SA: Smoking among psychiatric outpatients: Relationship to substance use, diagnosis, and illness severity. Psychol Addict Behav 17: 259-265, 2003.

84. de Leon J and Diaz FJ: A meta-analysis of worldwide studies demonstrates an association between schizophrenia and tobacco smoking behaviors. Schizophr Res 76: 135-157, 2005.

85. Gilbody S, Peckham E, Bailey D, Arundel C, Heron P, Crosland S, Fairhurst C, Hewitt C and Li J; members of the SCIMITAR+ collaborative: Smoking cessation in severe mental illness: Combined long-term quit rates from the UK SCIMITAR trials programme. Br J Psychiatry 18: 95-97, 2021.

86. Thomson D, Berk M, Dodd S, Rapado-Castro M, Quirk SE, Ellegaard PK, Berk L and Dean OM: Tobacco use in bipolar disorder. Clin Psychopharmacol Neurosci 13: 1-11, 2015.

87. Li XH, An FR, Ungvari GS, Ng CH, Chiu HFK, Wu PP, Jin X and Xiang YT: Prevalence of smoking in patients with bipolar disorder, major depressive disorder and schizophrenia and their relationships with quality of life. Sci Rep 7: 8430, 2017.

88. Arnson Y, Shoenfeld Y and Amital H: Effects of tobacco smoke on immunity, inflammation and autoimmunity. J Autoimmun 34: J258-J265, 2010.

89. Lee J, Taneja V and Vassallo R: Cigarette smoking and inflammation: Cellular and molecular mechanisms. J Dent Res 91: 142-149, 2012.

90. Cattaruzza MS, Zagà V, Gallus S, D'Argenio P and Gorini G: Tobacco smoking and COVID-19 pandemic: Old and new issues. A summary of the evidence from the scientific literature. Acta Biomed 91: 106-112, 2020.

91. Polverino F: Cigarette smoking and COVID-19: A complex interaction. Am J Respir Crit Care Med 202: 471-472, 2020.

92. Reddy RK, Charles WN, Sklavounos A, Dutt A, Seed PT and Khajuria A: The effect of smoking on COVID-19 severity: A systematic review and meta-analysis. J Med Virol 93: 1045-1056, 2021.

93. Lombardi C, Roca E, Ventura L and Cottini M: Smoking and COVID-19, the paradox to discover: An Italian retrospective, observational study in hospitalized and non-hospitalized patients. Med Hypotheses 146: 110391, 2021.

94. Usman MS, Siddiqi TJ, Khan MS, Patel UK, Shahid I, Ahmed J, Kalra A and Michos ED: Is there a smoker's paradox in COVID-19? BMJ Evid Based Med: Aug 11, 2020 (Epub ahead of print).

95. Edmonston DL, South AM, Sparks MA and Cohen JB: Coronavirus disease 2019 and hypertension: The role of angiotensin-converting enzyme 2 and the renin-angiotensin system. Adv Chronic Kidney Dis 27: 404-411, 2020.

96. Vleeming W, Rambali B and Opperhuizen A: The role of nitric oxide in cigarette smoking and nicotine addiction. Nicotine Tob Res 4: 341-348, 2002.

97. Akerström S, Mousavi-Jazi M, Klingström J, Leijon M, Lundkvist A and Mirazimi A: Nitric oxide inhibits the replication cycle of severe acute respiratory syndrome coronavirus. J Virol 79: 1966-1969, 2005.

98. Czuczwar M, Kiś J, Czuczwar P, Wielosz M and Turski W: Nicotine diminishes anticonvulsant activity of antiepileptic drugs in mice. Pol J Pharmacol 55: 799-802, 2003.

99. Reinsberger C, Dorn T and Krämer G: Smoking reduces serum levels of lamotrigine. Seizure 17: 651-653, 2008.

100. Tsuda Y, Saruwatari J and Yasui-Furukori N: Meta-analysis: The effects of smoking on the disposition of two commonly used antipsychotic agents, olanzapine and clozapine. BMJ Open 4: e004216, 2014

101. Oliveira P, Ribeiro J, Donato H and Madeira N: Smoking and antidepressants pharmacokinetics: A systematic review. Ann Gen Psychiatry 16: 17, 2017.

102. Bobes J, Arango C, Garcia-Garcia M and Rejas J: Healthy lifestyle habits and 10-year cardiovascular risk in schizophrenia spectrum disorders: An analysis of the impact of smoking tobacco in the CLAMORS schizophrenia cohort. Schizophr Res 119: 101-109, 2010.

103. Chao AM, White MA, Grilo CM and Sinha R: Examining the effects of cigarette smoking on food cravings and intake, depressive symptoms, and stress. Eat Behav 24: 61-65, 2017. 
104. Alsuwaidan MT, Kucyi A, Law CW and McIntyre RS: Exercise and bipolar disorder: A review of neurobiological mediators. Neuromolecular Med 11: 328-336, 2009.

105. Sylvia LG, Ametrano RM and Nierenberg AA: Exercise treatment for bipolar disorder: Potential mechanisms of action mediated through increased neurogenesis and decreased allostatic load. Psychother Psychosom 79: 87-96, 2010.

106. Kay-Lambkin FJ, Thornton L, Lappin JM, Hanstock T, Sylvia L, Jacka F, Baker AL, Berk M, Mitchell PB, Callister R, et al: Study protocol for a systematic review of evidence for lifestyle interventions targeting smoking, sleep, alcohol/other drug use, physical activity, and healthy diet in people with bipolar disorder. Syst Rev 5: 106, 2016.

107. Cuomo A, Giordano N, Goracci A and Fagiolini A: Depression and vitamin D deficiency: Causality, assessment, and clinica practice implications. Neuropsychiatry (London) 7: 606-614, 2017.

108. Cuomo A, Maina G, Bolognesi S, Rosso G, Beccarini Crescenzi B Zanobini F, Goracci A, Facchi E, Favaretto E, Baldini I, et al: Prevalence and correlates of vitamin D deficiency in a sample of 290 inpatients with mental Illness. Front Psychiatry 10: 167, 2019.

109. Hansdottir S, Monick MM, Lovan N, Powers LS and Hunninghake GW: Smoking disrupts vitamin D metabolism in the lungs. Am J Respir Crit Care Med 181: A1425, 2010.

110. Lange NE, Sparrow D, Vokonas P and Litonjua AA: Vitamin D deficiency, smoking, and lung function in the normative aging study. Am J Respir Crit Care Med 186: 616-621, 2012.

111. Uh ST, Koo SM, Kim YK, Kim KU, Park SW, Jang AS, Kim DJ, Kim YH and Park CS: Inhibition of vitamin D receptor translocation by cigarette smoking extracts. Tuberc Respir Dis (Seoul) 73: $258-265,2012$

112. Gejman PV, Sanders AR and Duan J: The role of genetics in the etiology of schizophrenia. Psychiatr Clin North Am 33: 35-66, 2010.

113. Kerner B: Genetics of bipolar disorder. Appl Clin Genet 7: 33-42, 2014.

114. Shadrina M, Bondarenko EA and Slominsky PA: Genetics factors in major depression disease. Front Psychiatry 9: 334, 2018.

115. Kaser A: Genetic risk of severe covid-19. N Engl J Med 383: 1590-1591, 2020.

116. Pairo-Castineira E, Clohisey S, Klaric L, Bretherick AD, Rawlik K Pasko D, Walker S, Parkinson N, Fourman MH, Russell CD, et al: Genetic mechanisms of critical illness in Covid-19. Nature 591: 92-98, 2021.

117. Zeberg H and Pääbo S: The major genetic risk factor for severe COVID-19 is inherited from Neanderthals. Nature 587: 610-612, 2020.

118. Rigat B, Hubert C, Alhenc-Gelas F, Cambien F, Corvol P and Soubrier F: An insertion/deletion polymorphism in the angiotensin I-converting enzyme gene accounting for half the variance of serum enzyme levels. J Clin Invest 86: 1343-1346, 1990.

119. Wu Y, Wang X, Shen X, Tan Z and Yuan Y: The I/D polymorphism of angiotensin-converting enzyme gene in majo depressive disorder and therapeutic outcome: A case-control study and meta-analysis. J Affect Disord 136: 971-978, 2012.

120. Kucukali CI, Aydin M, Ozkok E, Bilge E, Zengin A, Cakir U and Kara I: Angiotensin-converting enzyme polymorphism in schizophrenia, bipolar disorders, and their first-degree relatives Psychiatr Genet 20: 14-19, 2010.

121. Mazaheri H and Saadat M: Association between insertion/deletion polymorphism in angiotension converting enzyme and susceptibility to schizophrenia. Iran J Public Health 44: 369-373, 2015.

122. Crescenti A, Gassó P, Mas S, Abellana R, Deulofeu R, Parellada E, Bernardo $\mathrm{M}$ and Lafuente A: Insertion/deletion polymorphism of the angiotensin-converting enzyme gene is associated with schizophrenia in a Spanish population. Psychiatry Res 165: 175-180, 2009.

123. Song GG and Lee YH: The insertion/deletion polymorphism in the angiotensin-converting enzyme and susceptibility to schizophrenia or Parkinson's disease: A meta-analysis. J Renin Angiotensin Aldosterone Syst 16: 434-442, 2015

124. Nadalin S, Buretić-Tomljanović A, Rubeša G, Jonovska S, Tomljanović D and Ristić S: Angiotensin-converting enzyme gene insertion/deletion polymorphism is not associated with schizophrenia in a Croatian population. Psychiatr Genet 22: 267-268, 2012 .

125. Hui L, Wu JQ, Zhang X, Lv J, Du WL, Kou CG, Yu YQ, Lv MH, Chen DC and Zhang XY: Association between the angiotensin-converting enzyme gene insertion/deletion polymorphism and first-episode patients with schizophrenia in a Chinese Han population. Hum Psychopharmacol 29: 274-279, 2014.
126. Hui L, Wu JQ, Ye MJ, Zheng K, He JC, Zhang X, Liu JH, Tian HJ, Gong BH, Chen DC, et al: Association of angiotensin-converting enzyme gene polymorphism with schizophrenia and depressive symptom severity in a Chinese population. Hum Psychopharmacol 30: 100-107, 2015.

127. Baghai TC, Schule C, Zwanzger P, Minov C, Zill P, Ella R, Eser D, Oezer S, Bondy B and Rupprecht R: Hypothalamic-pituitary-adrenocortical axis dysregulation in patients with major depression is influenced by the insertion/deletion polymorphism in the angiotensin I-converting enzyme gene. Neurosci Lett 328: 299-303, 2020.

128. Bahramali E, Firouzabadi N, Yavarian I, Shayesteh MR, Erfani N, Shoushtari AA and Asadpour R: Influence of ACE gene on differential response to sertraline versus fluoxetine in patients with major depression: A randomized controlled trial. Eur J Clin Pharmacol 72: 1059-1064, 2016.

129. Delanghe JR, Speeckaert MM and De Buyzere M: The host's angiotensin-converting enzyme polymorphism may explain epidemiological findings in COVID-19 infections. Clin Chim Acta 505: 192-193, 2020.

130. Delanghe JR, Speeckaert MM and De Buyzere ML: COVID-19 infections are also affected by human ACE1 D/I polymorphism. Clin Chem Lab Med 58: 1125-1126, 2020.

131. Zajc Petranović M, Skarić-Jurić T, Smolej Narančić N, Tomas Z, Krajačić P, Miličić J, Barbalić $M$ and Tomek-Roksandić S: Angiotensin-converting enzyme deletion allele is beneficial for the longevity of Europeans. Age (Dordr) 34: 583-595, 2012.

132. Bellone $M$ and Calvisi SL: ACE polymorphisms and COVID-19-related mortality in Europe. J Mol Med (Berl) 98: 1505-1509, 2020.

133. Hatami N, Ahi S, Sadeghinikoo A, Foroughian M, Javdani F, Kalani N, Fereydoni M, Keshavarz P and Hosseini A: Worldwide ACE (I/D) polymorphism may affect COVID-19 recovery rate: An ecological meta-regression. Endocrine 68: 479-484, 2020.

134. Jakovac H: COVID-19 and hypertension: Is the HSP60 culprit for the severe course and worse outcome? Am J Physiol Heart Circ Physiol 319: H793-H796, 2020.

135. Meng J, Xiao G, Zhang J, He X, Ou M, Bi J, Yang R, Di W, Wang Z, Li Z, et al: Renin-angiotensin system inhibitors improve the clinical outcomes of COVID-19 patients with hypertension. Emerg Microbes Infect 9: 757-760, 2020.

136. Pirola CJ and Sookoian S: Estimation of ReninAngiotensin-Aldosterone-System (RAAS)-Inhibitor effect on COVID-19 outcome: A Meta-analysis. J Infect 81: 276-281, 2020.

137. Zhong Y, Zhao L, Wu G, Hu C, Wu C, Xu M, Dong H, Zhang Q, Wang G, Yu B, et al: Impact of renin-angiotensin system inhibitors use on mortality in severe COVID-19 patients with hypertension: A retrospective observational study. J Int Med Res 48: 300060520979151, 2020

138. Cetinkal G, Kocas BB, Ser OS, Kilci H, Yildiz SS, Ozcan SN, Verdi Y, Altinay M and Kilickesmez K: The association between chronic use of renin-angiotensin-aldosterone system blockers and in-hospital adverse events among covid-19 patients with hypertension. Sisli Etfal Hastan Tip Bul 54: 399-404, 2020.

139. Lee MMY, Docherty KF, Sattar N, Mehta N, Kalra A, Nowacki AS, Solomon SD, Vaduganathan M, Petrie MC, Jhund PS and McMurray JJV: Renin-angiotensin system blockers, risk of SARS-CoV-2 infection and outcomes from CoViD-19: Systematic review and meta-analysis. Eur Heart J Cardiovasc Pharmacother pvaa138 2020 (Epub ahead of prin).

140. Niederhofer H: Angiotensin converting enzyme inhibitors/estrogen/cortisol: Maybe an additional option in the treatment of psychiatrically disordered patients? Med Hypotheses 70: 703-704, 2008

141. Gadelha A, Vendramini AM, Yonamine CM, Nering M, Berberian A, Suiama MA, Oliveira V, Lima-Landman MT, Breen G, Bressan RA, et al: Convergent evidences from human and animal studies implicate angiotensin I-converting enzyme activity in cognitive performance in schizophrenia. Transl Psychiatry 5: e691,2015.

142. Wincewicz D and Braszko JJ: Validation of brain angiotensin system blockade as a novel drug target in pharmacological treatment of neuropsychiatric disorders. Pharmacopsychiatry 50: 233-247, 2017

This work is licensed under a Creative Commons Attribution-NonCommercial-NoDerivatives 4.0 International (CC BY-NC-ND 4.0) License. 